\title{
Creating Worlds: Notes On Hermeneutics of Communication
}

\section{Paolo Granata, University of Bologna, Italy}

\begin{abstract}
In this article I try to outline a hermeneutics of communication, in which the articulation of the discourse lies in the environmental component of media. Overcoming the conception of media understood only as technologies or tools at the service of communication, one understands their worth as expressive forms of the social and cultural environment. And, following this approach, one discovers that communication is not the transmission of messages, but rather an interactive, environmental, ecological system; it is an event, a selfreferential process strengthened by the interweaving of connections that form a system of global, participatory, and plural communication, created through proximity and through contact. In this way, there emerges a hermeneutics of communication which reveals its interlocutory and pragmatic aspects.
\end{abstract}


Nowadays, media system is widely and consistently referred to with the expression communication technologies. At the same time, as Palo Alto School pioneer Paul Watzlawick suggests in the axiom "one cannot not communicate" (Watzlawick et al. 1967), there exists in man an endemic need for communication that certainly can not be separated from his media. Every new medium is, therefore, accepted without reservation as a tool, a device for communication.

And yet, within the media system, there is a dominant role given to communication, a preferential role which seems to result from an oversimplification of the function and cultural potential of the media themselves; this phenomenon is especially evident in the emergence of mass society and with the diffusion of those means of communication that have been conveniently labeled mass media. This issue was highlighted by Marshall McLuhan (1964) wherein he refers to communication as a typology or function highly important to, but not the exclusive means of, mediation with the world, and attributes to the media not only a communicative purpose, but also a much larger role in the formation of intellectual, sensorial and aesthetic experience. In McLuhan's view, the media are not merely simple tools, nor do they serve only for communicating. It is clear, then, that the same celebrated aphorism "the medium is the message" should be interpreted with less emphasis on what the media transmit, that is, on their merely informative content, and more emphasis on how the media function, that is, on the processes by which they influence the perceptive and aesthetic-cognitive spheres, on how they massage the common sensorium - from this concept, the later reformulation of the famous slogan into "the medium is the massage" (McLuhan, Fiore 1967) -, and on how they produce significant changes in the modalities of interaction and mediation with the world. Nevertheless, McLuhan's thinking has also, to some extent, fallen prey to the paradigm which views communication as the dominant function of media. Too often, the emphasis has been placed on the communication of a message while neglecting the environmental and experiential dimension of the media, a dimension exemplified by another axiom, famous though sometimes misunderstood - the global village (McLuhan 1962). As is known, McLuhan was one of the first to speak of a new environmental and existential dimension of media, a retribalization capable of fostering a sense of community and of facilitating archetypal forms of experience - a contemporary nomadism, as it was expressed in the metaphor of man as "food-gatherer" (1964). And yet, despite the proclamations of McLuhan, the logic intrinsic to the media - in other words, the combination of the processes 
of experiential interaction with the world as it is conceived in the archetype of a tribal village - has been misinterpreted because of the exaggerated focus on communication and because of the unsettling tendency to understand message as synonymous with information, in other words, as something to be planted, rather than something to be gathered. In this sense, many of the discourses pertaining to the electronic age - first and foremost, to radio and television have contributed to the creation of a way of thinking in which global has become synonymous with standardizing, in which communication refers to mass communication, and in which the idea of transmission has prevailed over the process of interaction.

Today, in the so-called digital world, the over-used and out-dated image of the global village, emblem of the media system rooted in electronics, i.e. the mass media, is slowly transforming into an undoubtedly lighter and more fluid image of a plural village, a differential dimension founded on a logic of access to a relational network of meanings shared on both collective and subjective levels, otherwise described in terms of personal media. It should be pointed out that this phenomenon of transformation, transition, and hybridization is not as sudden as many observers have suggested. And if there is value in these new experiential conditions of the digital world, that value comes from renewing the very meaning of media (and in this sense, they deserve the title of new media) and from refocusing interpretive attention - too often biased in favor of the message misunderstood as mere information and communication - on the idea of medium as process, with all of its active relationships of meaning. Moreover, this rebalancing represents a redeeming epistemic shift which offers a new interpretive key for the concept of communication itself. The shift from what to how, in other words, the jump back from the message to the medium, highlights the need to rethink the hermeneutics of communication: no longer communication which crosses the world, but rather communication which creates worlds.

At this point, it would be worthwhile to introduce another idea of communication - as an experiential space - that arises from a semantic-lexical observation: the emergence of digital media has brought about a pragmatic substitution of the concept of reading/vision with that of navigation/exploration. In particular, the metaphor of navigation suggests that every type of text - and, by extension, every communicative experience - becomes a space to explore, capable, that is, of generating a relational interaction. As regards the very concept of communication, this semantic shift is highly appropriate and revealing. For the idea of 
transmission - canonically understood as the essence of every act of communication - we should substitute the idea of interaction. In this respect, it's interesting to note that the root of the Latin word communis derives directly from the cultural concept of exchange and giftgiving. Cum, "with", recalls precisely this idea of sharing, while the adjective munis in Latin indicated an obligation, a debt, a reciprical bond, or even a true and proper gift (Ronchi 2003). In other words, one could translate communis as a free and open sharing of experience that emerges from interaction in and around a common space. However, this lexical substitution something a bit more than a simple semantic shift - does not come without its difficulties, due to the frequency with which every process of communication is conventionally described using the metaphor of the transmission and exchange of messages. In no uncertain terms, we can say that this is a misinterpretation of the famous mathematical theory of communication proposed in the mid-Twentieth century by Claude Shannon and Warren Weaver; a misinterpretation reiterated in the following years, consolidated in the most diverse areas of intellectual thought, absorbed by the most varied lexical and cultural conventions. In the words of Weaver, information "relates not so much to what you do say, as to what you could say. That is, information is the measure of your freedom of choice when you select a message" (Shannon, Weaver 1949: 8-9).

In opposition to the mathematical theory of communication, the Palo Alto School - from Bateson to Goffman and Watzlawick - amended the logical-abstract conception proposed by Shannon and Weaver, introducing a relational view of communication which emphasized its interlocutory, behaviorist, pragmatic and contractual nature. So, at this point, we should make a first essential distinction, in agreement with what has been argued by Paolo Vidali, who writes: "Information is not a message, but a process, and its quantification is defined in terms of a reduction of uncertainty for all possible events, taking into consideration their respective probabilities" (Vidali 1993: 318). Confusing the information for the message, therefore, is equivalent to mistaking an operation for an object, or, in other words, mistaking the vehicles of potential information with the information itself. Rather than a mere transmission of information, what occurs is a transmission of data or signs; these data and signs then undergo a process of reduction of uncertainty resulting in what we call information. Chilean biologists Maturana and Varela describe this process in reference to the distinction between the denotative and connotative use of language: 
So long as language is considered to be denotative it will be necessary to look at it as a means for the transmission of information, as if something were transmitted from organism to organism, in a manner such that the domain of uncertainties of the 'receiver' should be reduced according to the specifications of the 'sender'. However, when it is recognized that language is connotative and not denotative, and that its function is to orient the orientee within his cognitive domain without regard for the cognitive domain of the orienter, it becomes apparent that there is no transmission of information through language [...] In a strict sense then, there is no transfer of thought from the speaker to his interlocutor; the listener creates information by reducing his uncertainty through his interactions in his cognitive domain. (Maturana,Varela 1980: 32).

The act of communication should be understood as a constant redefinition of one's own inner world, a continuous cognitive reorganization, a reevaluation of one's self within a relational system. Interaction thus represents the structural model typical of communicative experience, which in turn assumes the characteristics of a continuous choice, a continuous cognitive transformation, and therefore, an arbitrary decision, a conscious adaptation to the numerous stimuli in the perceptive and sensorial sphere triggered by all the material and intellectual tools - first and foremost, by language - that constitute experience itself. From this point of view, new media should be considered as a relational system capable of constructing, within themselves and according to their own logic, a place for themselves, a space, and, thus, an experience. This system is closed, wherein the closure should be understood as the result of an individual construction, a subjective experience of communication capable of modifying, from the inside, the referential system as a whole, which is itself, in turn, considered the very element of the process of communication. Thinking of communication as systemic closure concludes Vidali - requires, therefore, "understanding it as a constructive process, not one of transmission", on the basis of which emerges a different idea of language, "understood as world and not as tool", within a process in which "only a change in the system reveals that the actual communicative experience occurred. [...] A change that becomes the medium, a cognitive environment with a different orientation, and a richer variety of possible formulations, possibilities of diverse messages" (Vidali 1993: 329).

Pierre Lévy proposes a similar concept in what he calls a hermeneutic theory of 
communication (Lévy 1990). With Heidegger and Gadamer, among others, the hermeneutic approach has placed self-referential pre-understanding at the base of every interpretive act. But Lévy goes further - perhaps closer to the cognitivism of Neisser, Miller, and Chomsky identifying as the basis of interpretive activity a process of association, of linking, of the connection of a text to other texts and to the web of objective and subjective relationships in which it is inserted. Consequently, the meaning of a message is not determined only by its context. Rather, its effect is manifested in the moment in which the meaning of the message intervenes to modify, amend and create new relationships within the shared contextual web. He writes:

The basic model of communication is no longer ' $a$ transmits something to $b$ ', but rather ' $a$ modifies a configuration common to $a, b, c$, etc.'. The main object of a hermeneutic theory of communication is therefore neither the message, nor the sender, nor the receiver, but hypertext, which is like an ecological niche, the ever mobile system of relations of meaning in which the preceding ones are involved. The principal operators in this theory are not the coding, the decoding or the struggle against the noise of redundancy, but instead the molecular operations of association or disassociation that produce the continual metamorphosis of meaning (Lévy 1990: 81).

For Lévy, the use of the metaphor of hypertext is necessary to illustrate the recursive structure of meaning, that is, the network of shared elements that continuously transform themselves to reach a common meaning, a common place - true protagonist of the processes of communication - that the adaptive structure of the digital world reveals in all its transparency.

Following a theoretical approach, in his essay entitled Against the Standard Theory of Communication, Lucio Nanni centers his arguments around the need for a reconceptualization of communication. He writes:

Given a place (a culture), it's not its inhabitants who 'communicate' autonomously amongst themselves, but the place (the culture, that culture) that through them speaks with itself: manifest 'communication' between individuals as unseen self-communication of the place with itself, of a culture with itself. 
Self-communication, obviously, where no concept needs to pass through, to move from any part [...] because it has always been present in the same way in both the interlocutors. One does well then to put quotes around the word 'communication': you don't communicate anything; you only illuminate in unison something which is already common to both (Nanni 2001: 178).

On this same issue, some have even more pointedly highlighted the limitations of a materialist conception of communication. Dominique Wolton, for instance, has harshly criticized what she has defined as a true "techno-ideology of communication" (Wolton 2000), an ideology that is often the result of a misinterpretation of McLuhan's thinking, and what she sees, in many ways, as the expression of an intellectual orientation described in terms of a technological determinism.

Condemning the deterministic stance on the basis of which technology defines the content of communication, Wolton recognizes the need to reflect upon the ontological status of communication, lamenting the insufficient amount of attention given to the theoretical and scientific aspects of the issue within the contemporary interpretive paradigm; a paradigm which, saturated by the emergence of new digital technologies, seems more likely to generate an acritical attention to the questions and the problematics that communication raises, rather than to contribute to the their theoretical reassessment. The ontological perspective on communication - whose object is the relationship between man and the world - cannot be reduced to only an analysis of the performative impact of technological tools, which then ignores the cultural and social dimensions. In other words, argues Wolton, "it is not technology that communicates, but men and society" (Wolton 2000: 8). A strictly technical view of communication overshadows the environmental, human and social dimensions; the attention on the material aspects risks undermining the symbolic ones, causing a 'technicalization' of communication. One can thus assert - paraphrasing Heidegger - that the essence of communication is by no means anything communicative, and so neither instrumental nor materialistic, nor, as is often understood, transmissive. Only in the interweaving, in the ties and in the correspondences between the technical, cultural and societal factors is it possible to discern the essence of communication - only by socializing it, by humanizing it, by liberating it from the role of service or performance. 
Wolton distinguishes two specific dimensions of communication: one normative, the other functional. The first, which recalls the Medieval sense of the word communis, refers to the concept of sharing, understood on the ritual or experiential level; the second, more along the lines of its usage since the $17^{\text {th }}$ century, instead alludes to everything that has to do with diffusion, transition, transport, and that could easily align with the idea of McLuhan's pipeline model, understood as communication channel. These two dimensions stand in a relationship of dialectical opposition. In the model of normative communication - more consistent with the principle of human, interpersonal communication, with the subjective experience of communication - man acts within a cultural and social process which accesses all of the complexity and depth of its structures; it is a metacommunicative process in which he finds himself playing a role which is never neutral, but rather always subject to difficulty, to disappointments, to discomforts relating to communication and to the frequent breakdowns or impossibilities that arise; a process that is above all an experience of a cultural and social common - background. Functional communication, instead, is celebrated by the proponents of new media for its speed, accessibility, reliability and its overall effectiveness in everything related to the transmission process. In substance, however - Wolton suggests - its material aspects (the performative and technical dimensions) guarantee the semiotic pipeline, the transmission channel, but not the real experience of communication; the material factors provide only one of the possible measures for carrying out a potential reduction of uncertainty.

With this in mind, let's look again at what was expressed by Maturana and Varela. In fact, the concepts of normative and functional communication identified by Wolton can be interpreted as analogous to the denotative and connotative functions of language proposed by the pair of Chilean biologists. In the essay entitled The Tree of Knowledge, there is an explicit reference to the metaphor of the communications tube (or conduit) - the pipeline, in McLuhan's terminology:

According to our analysis, this metaphor is basically false. It presupposes a unity that is not determined structurally, where interactions are instructive, as though what happens to a system in an interaction is determined by the perturbing agent and not by its structural dynamics. It is evident, however, even in daily life, that such is not the case with communication: each person says what he says, or hears according to his own structural determination; saying does not ensure listening. From the perspective of an 
observer, there is always ambiguity in a communicative interaction. The phenomenon of communication depends not on what is transmitted, but on what happens to the person who receives it. And this is a very different matter from 'transmitting information' (Maturana, Varela 1987: 96).

We see a similar approach, as well, in the concept of metacommunication, as explained from a psychoanalytical perspective by Paul Watzlawick et al. (1976) in Pragmatics of Human Communication, wherein the attention falls on the relational aspect of every communicative event rather than on the context.

When considering the arguments rose above, it is particularly important to keep in mind the sheer extent to which digital technologies pervade all aspects of our contemporary social and cultural imagery. Since digital technologies carry with them an idea of communication strongly linked to technical and material factors, the contrast between the two hermeneutic models outlined above is evident. However, the potential of the digital world, understood as a new experiential space for communication, does not lie in the innovative material structures of which it is made, nor in the technological characteristics which distinguish it from 'old' mass media; its essential role resides, rather, in its intrinsic ability to reveal - and in so doing, to create a greater awareness of - the cultural models it transmits, highlighting the organizational process of the social system in which it manifests itself and accentuating all those relational components that belong to the model of communication known as normative.

The idea of new media as an autonomous and operative place, an environment, a space of everyday life, an arena for changing conceptions of communication and the production of new languages, a territory of new experiences and forms of subjectivity in which society reflects and immerses itself - this conception of new media is the key element of the process of coevolution between media and the world, a process situated on the epistemological border between society and technology. The trajectory that pushes communication towards new interpretive avenues is determined by the changes effected within the media system that - as in the evolution from the oldest oral forms through written language to the printing press and mass media - has now, with the most recent technological dimensions, begun again to reconfigure and articulate itself in never-before-seen forms. New media are structured more and more as worlds, built upon the interweaving of the delicate processes of communication 
which come together to form a cognitive space open to new types of experience; a profoundly revamped technological environment, experienced daily, and capable of simultaneously describing reality while neutralizing it, synthesizing it into a new meaningful entity, a new space of action and communicative capacity, which Giovanni Boccia Artieri (2004) encapsulated in the term media-mondo/media-world.

As with the earlier contributions mentioned, Boccia Artieri's consideration of the communicative experience challenges the common and widely assimilated understanding of communication as the simple transmission of a message between sender and recipient, the emphasis on informative function resulting from the theoretical-interpretive influence of Shannon and Weaver. In the media environment, communication creates worlds, an "independent reality in which information is no longer identifiable with the subjects who communicate because it transcends them, neutralizing the individual matters at hand" (Boccia Artieri 2004: 19). Detached from the singularities of the mere corporeal presence of the communicators - a condition often experienced in the new technological environment communication becomes something more than a simple communicative process. If we think of communication as creating worlds, information acquires the status of an event, an autonomous reality capable of transcending single subjective experiences. In this way, communication gains an element of autonomy - which above was defined in terms of selfcommunication (Nanni 2002) -, a true "developmental strategy of communication" (Boccia Artieri 2004: 35), an autopoiesis/self-production (Maturana,Varela 1980).

The digital world, in all its possible social and cultural expressions, becomes the principle intersection of new anthropological spaces, reflections of a nomadic culture (the food-gatherer theorized by McLuhan), an environment of communication, an arena of connection which puts subjects in contact with one another. From this perspective, new media should not be thought of as a reality unto themselves, but rather as a natural extension of the physical space experienced in quotidian, everyday life and in the corporeality of material reality, a space of new experiences where contents of meaning are forged, a space for the social construction of reality - evoking, in this regard, the social constructivism of the scholars Berger and Luckmann (1966).

The notions of synthetic communication and synthetic space, introduced by Fausto Colombo 
(1993), follow a similar line of analysis. Beginning with the revision of some interpretive parameters underlying the concept of communication, Colombo addresses the possibility of a logical-spatial redefinition of the new communicative environment established in the digital world, what he calls synthetic communication. The first element of revision concerns the representation of the idea of network, built on the mechanical and two-dimensional principle of connection between two points in space. Instead, he proposes for the processes of communication a model of topological representation taken from the study of energy, inspired by the metaphors of gravity and of magnetism. According to this theory, communication reshaped by new media technologies liberates itself from the idea of transmission wherein messages move from one place to another along a network of channels. Instead, the communication experience finds a new interpretation in the metaphor of information flow, that is, a combination of polarizing or orbiting energetic thrusts.

In this sense, the new media offer themselves as a synthetic space for communication; a space within which the temporal coordinates, by means of acceleration and instantaneity, assume a new perceptive form; a space in which the communicative action is everywhere, and time is capable of settling in any moment, contributing to the formation of "a technological environment that is increasingly akin to a sort of new penetrating and enveloping nature" (Colombo 1993: 295). The idea of flow thus overlaps the idea of space; a synthetic space, which both envelops and penetrates. Consequently, communicating with new media means sharing the same informative flow that itself constitutes the communication and makes it experienceable in all of its spatial dimension and - by virtue of the rationale specific to the place in which it happens - in all of the rules and conventions that make it an autonomous reality.

The idea of synthetic communication - of a technicological environment capable of synthesizing as well as modifying the processes and the rationale typical of all communication - calls to mind the proposal of techno-communication advanced by René Berger (1991). Once again the mathematical theory of communication, with its limits, its interpretations and, in this case, its omissions, is thoroughly analyzed and critiqued. According to Berger, two of these omissions are the most serious. The first consists in underestimating the role of interaction in communication, that is, the principle in which sender/receiver act primarily as participants in a common process rather than as mere 
transmitters or receivers; the second results from the lack of what Berger defines as a conditioning element, a sort of hidden understanding, that is, all the cultural elements specific to a group or to a society, necessary to the interlocutors so that communication may happen even outside of the particulars of the code. Berger's proposal, in essence, moves away from the need to relativize the importance of the Shannon and Weaver model and to circumscribe it within an engineering paradigm, conceived or founded on a sort of technical economy oriented to maximize efficiency with the goal of guaranteeing the transmission of messages in the most reliable way and at the least expense (Shannon, Weaver 1949). Instead, all digital technologies are involved in a process which the French art historian calls "rocket of technocommunication" (Berger 1991:20), a metaphor for expressing the conjunction of political, economic and technical factors whose interactions, rather than configure themselves as mere technical processes of transmission, strengthen into a "general system of communication", a techno-communicative paradigm, "in which we ourselves take part and in which we are called, maybe even unbeknownst to us, to play the roles that are assigned to us" (21). This paradigm assumes the appearance of a real "techno-communicative environment on a global scale", a place - the digital world - built from and on technology (23); an environment capable of revealing, to the fullest extent, the implicit acquisition of shared practices, of socially assimilated cultural models, of hidden intentionalities; an environment which recognizes that it belongs to a space of communication that acts rather than being acted upon, and in which information doesn't simply pass through, but is actually generated.

In surveying these contributions, I have tried to outline an ecological vision of communication, in which the articulation of the discourse lies in the environmental component of media. Abandoning and overcoming the conception of media understood only as technologies or tools at the service of communication, one understands their worth as expressive forms of the social and cultural environment. And, following this approach, one discovers that communication is not the transmission of messages, but rather an interactive, environmental, ecological system; it is an event, a self-referential process strengthened by the interweaving of connections that form a system of global, participatory, and plural communication created through proximity and through contact, exactly like the global village described by McLuhan. In this way, there emerges a hermeneutics of communication which reveals - in a properly tribal sense - its interlocutory and pragmatic aspects. Freed from its misinterpretation as mere transmission of information, communication is now better understood and more closely 
connected to participation, to dialogue, to correlation, to belonging, and, therefore, to the transformation over time of a society. 


\section{References}

Berger P.L., Luckmann T. (1966), The Social Construction of Reality, New York: Doubleday.

Berger R. (1991), Téléovision. Le nouveau Golem, Lausanne: Iderive.

Boccia Artieri G. (2004), I media-mondo. Forme e linguaggi dell'esperienza contemporanea, Rome: Meltemi.

Colombo F. (1993), "La comunicazione sintetica", in Bettetini G., Colombo F. (eds.), Le nuove tecnologie della comunicazione, Milan: Bompiani, pp. 265-297.

Lévy P. (1990), Les technologies de l'intelligence. L'avenir de la pensée à l'ére informatique, Paris: La Découverte.

Maturana H., Varela F. (1980), Autopoiesis and Cognition. The Realization of the Living, Dordrecht (Holland): Reidel.

- (1992) [1984], The Tree of Knowledge: The Biological Roots of Human Understanding, trans. Robert Paolucci, Boston: Shambala.

McLuhan M. (1964), Understanding Media, New York: McGraw-Hill.

- (1962), The Gutenberg Galaxy. The Making of Typographic man, Toronto: University of Toronto Press.

McLuhan M., Fiore Q. (1967), The Medium is the Massage. An Inventory of Effects, New York, London, Toronto: Bantam Books.

Nanni L. (2002), Il silenzio di Ermes, Rome: Meltemi.

Ronchi R. (2003), Teoria critica della comunicazione, Milan: Bruno Mondadori.

Shannon C.E., Weaver W. (1949), The Mathematical Theory of Communication, Urbana, Illinois: University of Illinois Press.

Vidali P. (1993), “Esperienza e comunicazione nei nuovi media”, in Bettetini G., Colombo F. (eds.), Le nuove tecnologie della comunicazione, Milan: Bompiani, pp. 299-330.

Watzlawick P., Beavin J.H., Jackson D.D. (1967), Pragmatic of Human communication, New York: Norton \& Co.

Wolton D. (2000), Internet, et après? Une théorie critique des nouveaux médias, Paris: Flammarion. 